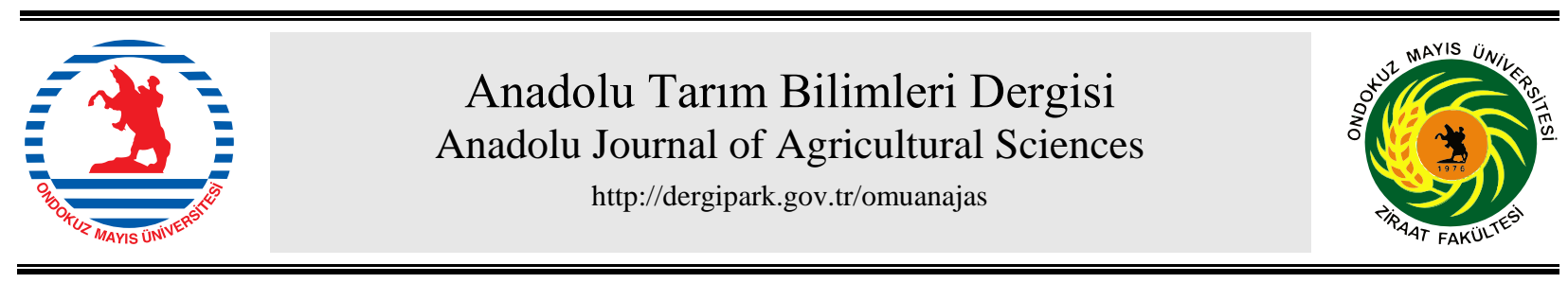

Araştırma/Research

Anadolu Tarım Bilim. Derg./Anadolu J Agr Sci, 34 (2019)

ISSN: 1308-8750 (Print) 1308-8769 (Online)

doi: $10.7161 /$ omuanajas. 541490

\title{
Karacadağ yöresinde biçerdöverle çeltik hasadında dane kayıplarının belirlenmesi
}

\author{
Reşat Esgici ${ }^{*}$, Mehmet Tunç Özcan ${ }^{\mathrm{b}}$ \\ ${ }^{a}$ Dicle Üniversitesi, Bismil Meslek Yüksekokulu, Diyarbakır \\ ${ }^{b}$ Çukurova Üniversitesi, Ziraat Fakültesi, Tarım makinaları ve Teknolojileri Mühendisliği Bölümü, Adana \\ *Sorumlu yazar/Corresponding author: resgici@dicle.edu.tr
}

Geliş/Received 18.03.2019 Kabul/Accepted 29.07.2019

\begin{abstract}
ÖZET
Diyarbakır ili, Karacadağ yöresi ülkemizin için önemli çeltik üretim bölgelerinden birisidir. Bölgede çeltik tarımında mekanizasyon uygulamaları oldukça yenidir. Bu yüzden biçerdöverle yapılan hasatta ürün kayıpları yüksektir. Çalışmanın temel amacı Karacadağ yöresinde biçerdöverle yapılan çeltik hasat-harmanında kullanılan tahıl biçerdöverinin neden olduğu dane kayıpları, nedenleri ve azaltma yollarını ortaya koymaktır. Denemeler bir üreticiye ait Karacadağ beyaz çeltik çeşidinin ekili olduğu tarlada üç farklı dönemde; üç farklı tane nem içeriğinde ( \% 22.10, 24.81 ve 28.81 ürün nem içeriğinde), üç farklı biçerdöver ilerleme hızında $\left(1.6 \mathrm{~km} \mathrm{~h}^{-1}, 3.2 \mathrm{~km} \mathrm{~h}^{-1}\right.$ ve $\left.4.8 \mathrm{~km} \mathrm{~h}^{-1}\right)$ ve dört farklı batör devrinde $\left(600,700,800\right.$ ve $\left.900 \mathrm{~min}^{-1}\right)$ yürütülmüştür. Denemelerde NEW HOLLAND TC 56 marka biçerdöver kullanılmıştır. Yapılan varyans analizi sonuçlarına göre seçilen bağımsız parametrelerin tane kayıplarına etkisinin önemli olduğu bulunmuştur $(p<0.01)$. Denemeler sonucunda elde edilen verilere göre dane nem içeriği ve batör devrinin artması; toplam hasat kayıplarını azaltırken, buna karşın biçerdöver ilerleme hızının artışı ise toplam hasat kayıplarını artırmıştır. Toplam hasat kayıpları üzerine biçerdöver ilerleme hızının (besleme miktarının artışı) etkisi ise artırıcı yönde olmuştur. Batör devir sayısının artışına bağlı olarak kırık tane arttığından toplam hasat kayıplarında önemli oranda düşüş meydana gelmiştir. Toplam hasat kayıpları için tüm deneme kombinasyonları etkisi ayrı ayrı değerlendirildiğinde en düşük hasat kaybı değeri $\% 28.85$ nem, $4.8 \mathrm{~m} \mathrm{~s}^{-1}$ ilerleme hızında ve $900 \mathrm{~min}^{-}$ ${ }^{1}$ 'llk batör devrinde \% 4.00 olarak, en yüksek değer ise $\% 24.81$ ürün nem içeriğinde $3.2 \mathrm{~km} \mathrm{~h}^{-1}$ biçerdöver ilerleme hızında ve $600 \mathrm{~min}^{-1}$ l, $1 \mathrm{k}$ batör devrinde \%16.97 olarak gerçekleşmiştir.
\end{abstract}

\section{Harvesting and threshing mechanization of rice in Karacadağ region}

\begin{abstract}
Karacadağ region of Diyarbakır province is one of the important paddy production regions of our country. Mechanization practices in paddy agriculture in the region are quite new. So, grain losses are high during harvesting with combine harvester. The main purpose of this study was to determine the grain losses, causes and ways of reducing the grain harvesters used in the paddy harvesting-threshing harvesting in Karacadağ region. The experiments were carried out in three different periods in the field where a Karacadağ white variety belonging to a producer was planted; three different grain moisture content $(22.10 \%, 24.81$ and 28.81 crop moisture content), three different combine forward speeds (1.6 $\mathrm{km} \mathrm{h}-1,3.2 \mathrm{~km} \mathrm{~h}-1$ and $4.8 \mathrm{~km} \mathrm{~h}-1)$ and four different drum speeds (600, 700), 800 and $900 \mathrm{~min}-1)$. NEW HOLLAND TC 56 combine harvester was used in the trials. The analysis of variance the main effects of moisture content, forward speeds and drum speed significantly affected grain losses. Test results indicated that total grain losses decreases with increase moisture content and drum speed. Also, forward speed has been increased the total grain losses. When the effect of all testing combination was evaluated together, the lowest total grain loses was found at $28.85 \%$ moisture content, $4.8 \mathrm{~km} \mathrm{~h}^{-1}$ forward speed and $900 \mathrm{~min}^{-1}$ drum speed as $4.0 \%$ while the highest total grain loses was found at
\end{abstract} $24.81 \%$ moisture content, $3.2 \mathrm{~km} \mathrm{~h}^{-1}$ forward speed and $600 \mathrm{~min}^{-1}$ drum speed as $16.97 \%$.

Anahtar Sözcükler:

Çeltik

Hasat-harman

Biçerdöver

Karacadağ

\section{Giris}

İnsanların kalori gereksinimlerinin en büyük bölümü pirinçten sağlanmaktadır. Dünyada 100'den fazla ülkede pirinç üretimi için çeltik tarımı yapılmaktadır. Üretimin $\% 91$ 'i Asya ülkeleri olmak üzere 156 milyon ha'lık alanda toplam 650 milyon ton çeltik üretimi gerçekleştirilmektedir (Anonyoums, 2008). Genellikle

Bu makale doktora tezinden üretilmiştir. 
Asya kıtasında yetiştirilen çeltik (Oryza sativa L.) dünyada olduğu gibi ülkemizde de insan beslenmesinin temel kaynağını oluşturması bakımından önemli bir tarımsal üründür. Türkiye'de çeltik ekim alanlarında yıldan yıla dalgalanmalar göstermesine rağmen TÜIK 2010 yılı verilerine göre 990 bin da'lık üretim alanından 860 bin ton ürün elde edilmiş ve ortalama verim $869 \mathrm{~kg}$ $\mathrm{da}^{-1}$ olarak gerçekleşmiştir. Marmara ve Karadeniz bölgeleri başta olmak üzere mevcut illerimizin çoğunda çeltik tarımı yapılabilmektedir. Çeltik üreten iller arasında Edirne ilk sırayı alırken onu Samsun, Balıkesir, Çanakkale, Çorum, Şanlıurfa, Tekirdağ ve Diyarbakır illeri izlemektedir. Ülkemizin çoğu bölgesinde çeltik yetiştirilmesine rağmen Doğu ve Güneydoğu Anadolu Bölgesinde çeltik yetiştiriciliğinin yapıldığı tek yer GAP Projesi kapsamında yer alan Karacadağ yöresidir (Şanlıurfa, Diyarbakır ve Mardin üçgeni).

TUIK 2010 verilerine göre, Güneydoğu Anadolu Bölgesinde çeltik ekim alanı yaklaşık 58 bin da (\% 6.1), pirinç üretimi 30 bin ton (\%3.6) verim ise $455 \mathrm{~kg} \mathrm{da}^{-1}$ civarındadır. Çeltik ekim alanlarının ve üretiminin de \%95'i Karacadağ yöresinde gerçekleşmektedir (Anonymous, 2011). İller bazında ise Şanlıurfa ili 33 bin da'lık üretim alanıla ilk sırada yer alırken, Diyarbakır ili 24 bin da'lı üretim alanıyla ikinci sırada, Mardin ili ise 1165 da'lık üretim alanıyla üçüncü sırada yar almaktadır.

Dolayısıla, bölge büyük bir ürün yetiştirme ve üretim potansiyeli olmasına rağmen verim değeri, ülke ortalamasından yaklaşık iki kat daha azdır. Bölgede çeltik tarımında mekanizasyon uygulamaların yetersiz olup, üretimin önemli bir kısmı insan işgücüne dayalı olarak gerçekleşmektedir. $\mathrm{Bu}$ nedenle, ürün verimi Türkiye ortalamasının çok altında kalmaktadır. Ürün verimi ve kayıpları üretim alanına bağlı olarak da değişmektedir. Karacadağ yöresinde çeltik tarımı ağırlıklı olarak taşlık alanlarda yapılmaktadır. Bu nedenle hasat kayıpları fazladır. Bu yüzden, verimliliğin artırılması, kayıpların azaltılması ve kalitenin korunması kırsal alanlarda mekanizasyon araçlarının kullanımının yaygınlaştırılması ve geliştirilmesiyle olanaklı hale gelebilecektir. Ayrıca, çeltik tarımında uygun hasatharman yönteminin seçilmesi ve zaman kaybının azaltılması kalitenin korunması açsından da önemlidir (Sessiz ve Pinar, 1999).

Son yıllarda lezzet ve doğal yetiştirme özelliğinden dolayı Karacadağ pirincine olan talep arttığından artık Karacadağ yöresinde çeltik üretimi sadece taşlık ve verimsiz alanlarda değil düz ve verimli alanlarda da yapılmaktadır. Düz alanlarda çeltik hasadı doğrudan biçerdöverle yapılırken, makinenin giremediği meyilli ve taşlık alanlarda hasat- tamamen insan tarafindan orakla yapılmakta ve harmanlamam işlemi ise durağan olarak çalışan biçerdöverlerle yapılmaktadır. Her iki durumda da ürün kayıplarının yüksek olduğu çeltik üretimi yapan çiftçiler tarafından ifade edilmiştir. Biçerdöverle hasatta biçerdöverin çalışma parametrelerinin ürünün özelliklerine uygun olarak ayarlanması ürün kayıplarının, zamanın ve emeğin azaltılması bakımından oldukça önemlidir. Ülkemi genelinde olduğu gibi Bölgemizde de, sezon itibariyle sonbaharın yağışlarına denk gelmesi ve ürünün sulu ortamda yetiştirilme özelliğinden dolayı çeltik tarımında görülen en büyük sorun hasat ve harmanlamadır. Özellikle, biçerdöverlerin hasat ve harmanlama üniteleri çeltik bitkisinin özelliklerine uygun değişiklikler yapılmadığından, yüksek oranda tane kayıplarının oluşumuna neden olmaktadır (Siebenmorgen ve ark., 1994; Sessiz ve ark., 1994; Sessiz ve Pinar, 1999; Sessiz ve ark., 2011).

Diğer tarımsal ürünlerin biçerdöverle doğrudan hasadı için, uygun çalışma parametrelerinin ve makine performansının belirlenmesi amacıyla çok sayıda çalışma yapılmasına rağmen, biçerdöver kullanılarak çeltik bitkisiyle yürütülen çalışma sayısı çok azdır. Bölgemizde ise doğrudan biçerdöverle çeltik hasadına yönelik yapılmış çalışma bulunmamaktadır. Bu durum çeltik mekanizasyonunda eksik olan doğrudan biçerdöverle hasat kısmının çalışılması gereğini ortaya çıkarmıştır. Biçerdöverle hasatta tane kayıplarını en aza indirmek için ilerleme hızı, batör-kontrbatör açıklığı, biçim yüksekliği ve dolap ayarı büyük önem taşımaktadır.

$\mathrm{Bu}$ çalışmada, mevcut tahıl biçerdöverini çeltik hasadında kullanılarak, farklı tane nem içeriklerinde, biçerdöverin farklı ilerleme hızlarında ve farklı batör devirlerinde biçerdöverin tarla koşullarında neden olduğu ürün kayıplarını ve biçerdöverle çeltik hasadında ürün kayıplarını azaltacak uygun çalışma parametrelerinin belirlenmesi amaçlanmıştır.

\section{Materyal ve Yöntem}

\subsection{Bitkisel materyal ve ölçüm cihazlarının özellikleri}

Hasat denemeleri Diyarbakır ili Çınar ilçesine bağlı ve Karacadağ bölgesinde bulunan Höyükdibi (Melkiş) köyünde bir çeltik üreticisine ait ve yörede yaygın olarak üretimi yapılan yerel Karacadağ beyaz çeltik çeşidinin ekildiği alanlarda yürütülmüştür. Biçerdöverle hasada başlanmadan önce tarlanın farklı noktalarından 1 $\mathrm{m}^{2}$ deki tane miktar1, bitki boyu, sap/dane oran1, başaktaki salkım sayısı, salkımdaki tane sayısı, 1000 dane ağırlığı, bitki sap ve dane nem içerikleri gibi fiziksel özellikleri belirlenmiştir. Ölçülen her bir fiziksel özellik için tarlanın farklı noktalarından alınan 25 bitki ile yapılmıştır. Buna ilişkin elde edilen ortalama değerler Çizelge 1'de verilmiştir.

$\mathrm{Bu}$ özelliklerin belirlenmesinde şerit metre, kumpas, elektronik terazi kullanılmıştır. Denemeler süresi boyunca bütün hassas tartım işleri Şekil 2'de görülen 0,1 hassasiyetli VIBBRA marka elektronik tartı ile yapılmıştır. Sap, salkım ve dane nem içeriklerinin belirlenmesinde Şekil 2'deki NUVE marka kurutma dolabı (Etüv) kullanılmıştır. Bitkiye ait fiziksel özelliklerin belirlenmesinde şerit metre ve kumpas kullanılmıştır.

Hasada başlanmadan önce her ürünün tane ve sap 
nem içeriğinin belirlenmesinde kurutma dolabından yararlanılmıştır. Hasat sırasında alınan dane ve sap örnekleri kap içerisine konularak laboratuvara getirilmiş ve hassas terazi ile tartılarak $105^{\circ} \mathrm{C}$ 'de 24 saat kurutma dolabında bekletilmiştir. 24 saatlik kurutma sonunda fırından alınan örnekler tekrar tartılarak ağırlığı belirlenmiştir (Sessiz ve Ülger, 1998; ASABE, 2008). Hasat sırasındaki dane nem içerikleri sırasıyla \%28.85, $\% 24.81$ ve $\% 22.10$ olarak bulunmuştur.

Çizelge 1. Çeltik bitkisine ait bazı özellikler

\begin{tabular}{lc}
\hline Özellikler & Ortalama değerler \\
\hline Ortalama verim $\left(\mathrm{kg} \mathrm{da}^{-1}\right)$ & 423 \\
Bitki boyu (cm) & 86.2 \\
Sap tane oranı & 2.27 \\
Salkım boyu (cm) & 16.4 \\
Salkımda tane sayısı (adet) & 79.1 \\
Salkımda salkımcık sayısı (adet) & 9.33 \\
Salkım çapı (mm) & 8.2 \\
1000 Tane ağırlı̆̆ $1(\mathrm{~g})$ & 32.27 \\
\hline Tane nem içeriği (\%) & \\
\hline $\mathrm{Wt}_{1}$ & 28.85 \\
$\mathrm{Wt}_{2}$ & 24.81 \\
$\mathrm{Wt}_{3}$ & 22.10 \\
\hline $\mathrm{Sap} \mathrm{Nem} \mathrm{İçeriği} \mathrm{( \% )}$ & \\
\hline $\mathrm{Ws}_{1}$ & 71.93 \\
$\mathrm{Ws}_{2}$ & 64.66 \\
$\mathrm{Ws}_{3}$ & 60.12 \\
\hline $\mathrm{Salkı} \mathrm{Nem} \mathrm{İçĭgi} \mathrm{( \% )}$ & \\
\hline $\mathrm{Wsk}_{1}$ & 30.55 \\
$\mathrm{Wsk}_{2}$ & 20.71 \\
$\mathrm{Wsk}_{3}$ & 18.23 \\
\hline
\end{tabular}

\subsection{Denemelerde kullanılan biçerdöver}

Hasat denemelerinde Şekil 1'de verilen ve doğrudan hasat işleminde kullanılan NEW HOLLAND TC 56 marka biçerdöver kullanılmıştır. Hasat döneminde bitki sap neminin yüksek olması nedeniyle oluşabilecek tıkanmaları önlemek amacıyla hasada başlanmadan önce biçerdöver üzerinde mevcut bulunan pervazlı tip harmanlama ünitesi parmaklı tip ile değiştirilmiş̧ir (Şekil 1).

\subsection{Biçerdöver ile yapılan tarla test çalışmaları ve çalışma parametreleri}

Çalışma üç farklı biçerdöver ilerleme hızlarında $\left(1.6,3.2\right.$ ve $\left.4.8 \mathrm{~km} \mathrm{~h}^{-1}\right)$ yürütülmüştür. Ürün yatık olmadığından tüm ilerleme hız değerlerinde dolap devir hızı makina ilerleme hızından \%25 fazla tutulmuştur (Staton ve Harrigan, 2008; Güzel ve ark., 2010). Makinenin ilerleme hızı sürücü tarafindan otomatik olarak ayarlanmış ve denemeler sırasında 50 m'lik mesafelerde bu değerin doğruluğu devir takometresiyle test edilmiştir. Bu hızlara bağglı olarak hasat kayıpları belirlenmiştir. Besleme miktarları değerleri makine ilerleme hızına bağlı olarak harmanlama ünitesine gönderilen saplı materyale göre yapılmıştır. Hasat işlemi tarla yüzeyinden $25 \mathrm{~cm}$ yükseklikte gerçekleşmiştir. Batör-kontrbatör açıklığı giriş ve çıkışta 2.2-4 cm arasında olacak şekilde sabit tutulmuştur (Quick, 1992; Andrews ve ark., 1993). Bu parametrelere bağlı olarak toplam kayıplar belirlenmiştir.

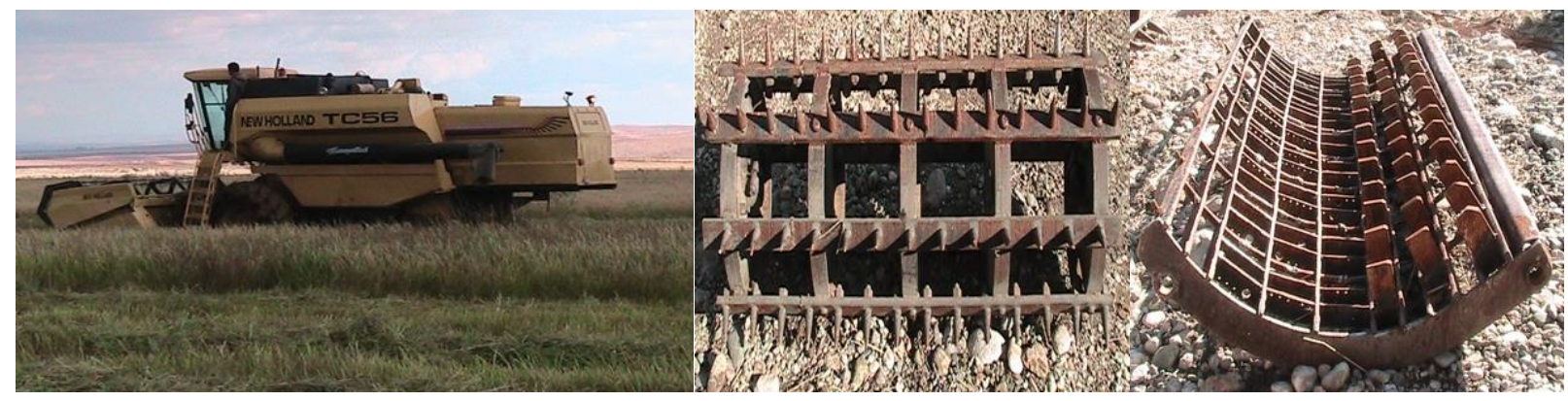

Şekil 1. Denemelerde Kullanılan New Holland TC 56 Biçerdöveri ve Denemelerde Kullanılan Parmaklı Tip Batör ve Kontrbatör

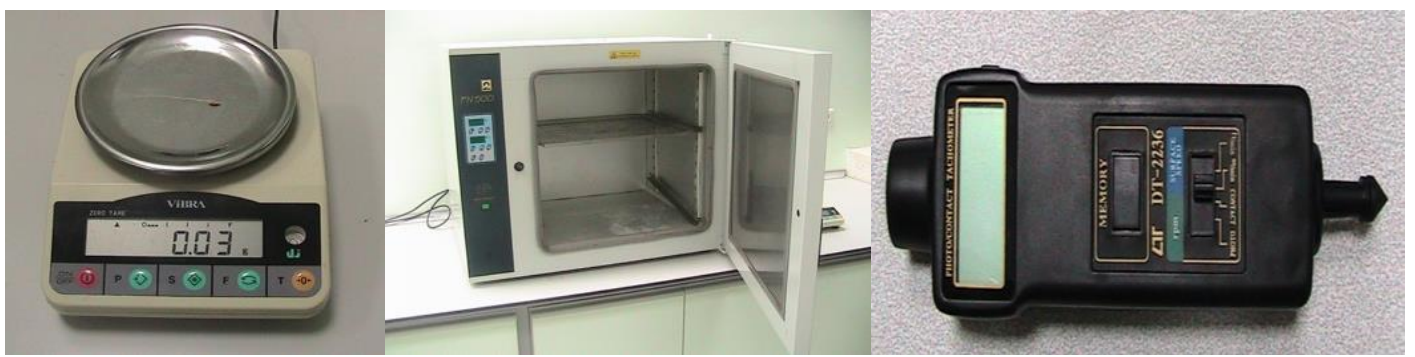

Şekil 2. Denemelerde Kullanılan Terazi, Kurutma Dolabı ve Devir Takometresi 


\subsection{Biçerdöver hasat kayıplarının belirlenmesi}

Hasat kayıpları; hasat öncesi makinadan kaynaklanmayan ve hasat sirasinda makinadan kaynaklanan kayıpların toplamından oluşmaktadır. Bu yüzden hasat kayıpları için hasat öncesi ve biçerdöverin hasat sırasında neden olduğu kayıplarının toplamı olan toplam tane kayıpları dikkate alınmıştır (Ülger, 1982, Dilmaç, 1982, Philbrook ve Oplinger, 1989; Roy ve ark., 2003; Sessiz ve ark., 2006; Staton ve Harrigan, 2008; Baran, 2010; Güzel ve ark., 2010). Çalışmanın yürütüldüğü deneme tarlasında biçerdöverle hasatta başlanmadan önce, tarlanın toplam tane verimi için tarlanın 10 değişik noktasında $1 \mathrm{~m}^{2}$ 'lik çerçeve kullanılarak $\mathrm{m}^{2}$, deki tane miktarı belirlenmiştir. Elde edilen değerler ortalama tane verimine dönüştürülmüştür (Ülger, 1982; Baran, 2010).

\subsection{Hasat öncesi kayıplar}

Biçerdöver ile hasat denemelerine başlanmadan önce hasat edilmeyen alandan $(1 \mathrm{~m}$ x $1 \mathrm{~m}) 1 \mathrm{~m}^{2}$ 'lik çerçeve kullanılarak tarlanın 10 farklı yerinden ölçümler alınmış ve çerçeve içinde kalan danelerin yanı sıra, yere düşmüş salkımların içindeki daneler de elle harmanlanarak tartılmıştır. Tüm danelerin ortalamaları alınarak $1 \mathrm{~m}^{2}$, deki hasat öncesi kayıplar tespit edilmiştir.

\subsection{Biçerdöver hasat kayıpları}

Toplam ürün kaybından hasat öncesi kayıpların çıkartılmasıyla elde edilen değer biçerdöver hasat kayıpları olarak dikkate alınmıştır. Makine kayıpları; başlık (tabla) ve harmanlama-ayırma kayıplarından oluşmaktadır. Biçerdöverlerde başlık kayıplarına makina çalışma parametreleri, çeşit, nem içeriği, dolap indeksi, biçme ünitesinin hızı, dolap devir hızı ile makina ilerleme hızı arasındaki ilişki sap uzunluğu, parmak açıklığı gibi faktörler etkilidir (Siebenmorgen ve ark., 1994; Chinswan ve ark., 1999; Junsiri ve Chinsuwan .,2009;; Sarkari, 2010; Güzel ve ark., 2010).

Başlık kayıpları dolabın çarpması sırasında dökülen, tablaya girmeden yere dökülen, parçalanan ve hasat edilmeyen ayaktaki bitkilerde kalan tanelerden oluşmaktadır. Hasat işlemi sırasında kayıpları belirlemek için, biçerdöver deneme düzenine uygun olarak ilerleme hızı, dolap ve batör devir sayıları ayarladıktan sonra hasada başlanmıştır. Hasat kayıplarının belirlenmesinde $1 \mathrm{~m}^{2}$ 'lik standart çerçeve kullanılmıştır (Şekil 3). Biçerdöver tarlada çeltik hasadına başladıktan sonra her bir hız denemesi için 50 m kadar biçme işlemi gerçekleştirilmiş (Roy ve ark., 2003) ve sonra ölçüm alınacak mesafe kadar biçerdöver geri çekilip, motor durdurulmuştur (Hofman ve ark., 1978; Jung, 1981; Güzel ve ark., 1991; Lesoing, 2001; Roy ve ark., 2003; Sumner, 2004; Sessiz ve ark., 2006). Geri çekilme işleminden sonra tabla kayıplarını ölçmek için hasat tablasının önündeki hasat edilmiş alana 6 $\mathrm{m}^{2}$ 'lik branda serilmiştir (Şekil 4). Hasat işlemi bitirildikten sonra brandanın altında kalan hasat edilmiş alanın üç farklı yerine $1 \mathrm{~m}^{2}$ 'lik çerçeve rastgele atılarak çerçeve içerisinde kalan taneler, yarım salkım ve tüm salkımlar toplanarak bir poşette konulmuş ve aynı gün laboratuvara getirilerek hassas terazi tartılmıştır. Aynı işlem üç kez tekrar edilmiştir.

Toplam hasat kayıpları için; makinanın arka kısmından hasat edilmiş yere $1 \mathrm{~m}^{2}$ lik dikdörtgen çerçeve yerleştirilerek ölçümler yapılmıştır. Çerçeve içerisinde kalan yerdeki danelerin yanı sıra, hasat edilemeyen salkımlardaki daneler de tartılmıştır (Şekil 3). Tartım sonucunda elde edilen taneler $\mathrm{m}^{2}$, deki taneye dönüştürülmüştür.

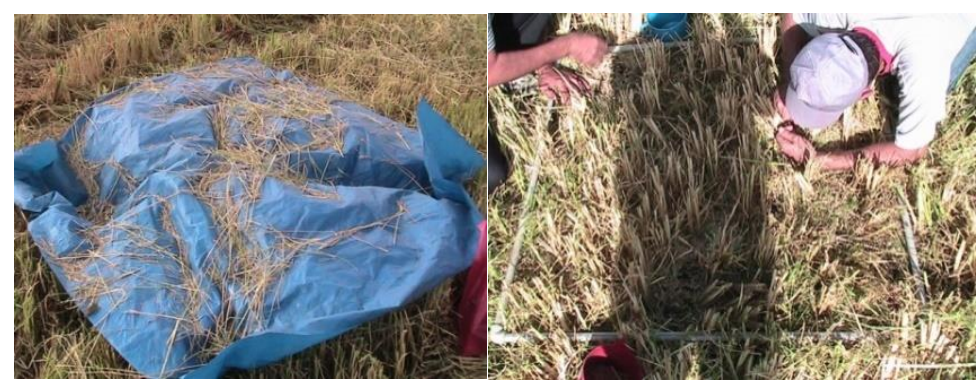

Şekil 3. Toplam Ürün Kaybını Belirlemek İçin Yapılan Sayım İşlemi

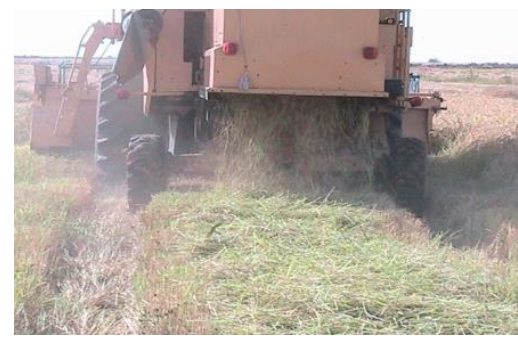

Şekil 4. Toplam Hasat Kayıplarının Ölçüldüğü Biçerdöverin Arka Kısmı 


\subsection{Harmanlama ve ayırma kayıplart}

Harmanlama ile ilgili daha önceleri yapılmış olan çalışmaların önerileri doğrultusunda 4 farklı batör devri (yaklaşık 600, 700, 800 ve $900 \mathrm{~min}^{-1}$ ) seçilmiştir (Andrews ve ark., 1993; Sessiz ve Ülger, 1998; Chinsuwan ve ark., 2003). Bu devir sayıları operatör tarafindan otomatik olarak ayarlanmış ve tarafımızdan dijital devir ölçer kullanılarak kontrol edilmiştir. Devir sayılarını çevre hızına dönüştürülmesinde aşağıda verilen eşitlik kullanılmıştır (Ülger, 1982; Sarwar ve Khan, 1987; Sessiz ve ark., 1994).

$$
V c ̧=\frac{\Pi D n}{60}
$$

Eşitlikte;

Vç: Batör çevre hızı $\left(\mathrm{m} \mathrm{s}^{-1}\right)$

D: Batör çapı (m)

n: Batör devir sayısı (d/d)

$\mathrm{Bu}$ devir sayılarına bağlı olarak harmanlama ünitesinin neden olduğu kırık dane ve harmanlanamayan salkım şeklindeki harmanlama kayıpları sarsak çıkışından alınan örneklerden sayım yapılarak belirlenmiştir. Harmanlama-ayırma kayıplarının belirlenmesinde $1 \mathrm{~m} \quad \mathrm{x} \quad 1 \mathrm{~m}$ çerçeve kullanılmıştır (Lesoing, 2001; Sessiz ve ark., 2006). Ayrica harmanlama ünitesinin neden olduğu kırık tane ve kavuzu soyulmuş tane oranını belirlemek için belirtilen ilerleme hızı ve batör devir hızında biçerdöver deposundan alınan örneklerden oluşan kırık veya kavuzu soyulmuş tane toplam örnek miktarına bölünerek harmanlama kayıpları bulunmuştur (ChuanUdom ve Chinsuwan, 2007; Hiregoudar ve ark., 2011).

\subsection{Istatistiksel analiz}

Denemeler farklı hasat zamanlarında deneme desenine uygun olarak tesadüf blokları deneme desenine göre üç tekerrürlü olarak yürütülmüştür. Denemelerden elde edilen veriler SPSS 17.0 ve JMP paket programı kullanılarak varyans analizlerine tabi tutulmuştur. Ortalamalar arasındaki farklılıklar LSD testine göre gruplandırılmıştır.

\section{Bulgular ve Tartışma}

Toplam biçerdöver hasat kayıpları; hasat öncesi kayıpları ile makine kayıplarının toplamından oluşan kayıplardır. Makine kayıpları olarak başlık kayıplar, harmanlama-ayırma kayıplarının toplamı olarak dikkate alınmıştır. Toplam hasat kayıplarına ilişkin varyans analiz sonuçları Çizelge 2'de Tukey testi ortalama sonuçları Çizelge 3'te ve sonuçların değişim grafiği Şekil 5'de verilmiştir. Varyans analizi çizelgesinden görüleceği gibi bütün bağımsız parametrelerinin ve interaksiyonlarının toplam hasat kayılarına etkisi istatistiksel olarak çok önemli $(\mathrm{p}<0.01)$ bulunmuştur.

Çizelge 2. Toplam Hasat Kayıplarına İlişkin Varyans Analizi

\begin{tabular}{lcll}
\hline V.K & S.D & K.T & F \\
\hline Nem & 2 & 156.88 & $89.16^{* *}$ \\
Hız & 2 & 38.94 & $22.13^{* *}$ \\
Devir & 3 & 510.70 & $193.51^{* *}$ \\
Nem x Hız & 4 & 259.23 & $73.67^{* *}$ \\
Nem x Devir & 6 & 15.36 & $2.91^{* *}$ \\
Hiz x Devir & 6 & 76.97 & $14.58^{* *}$ \\
Nem x Hiz x Devir & 12 & 105.66 & $10.00^{* *}$ \\
\hline
\end{tabular}

Çizelge 3. Toplam Hasat Kayıplarına İlişkin Tukey Testi Sonuçları*

Bağımsız parametre Toplam Makine

Kayıpları, \%

Nem içeriği (\%)

$22.10 \quad 9.76 \mathrm{a}$

24.81

$9.29 \mathrm{a}$

28.85

$7,00 \mathrm{~b}$

$\mathrm{LSD}_{0.05}$

0.549

Biçerdöver ilerleme Hızı $\left(\mathrm{km} \mathrm{h}^{-1}\right)$

$\begin{array}{ll}1.6 & 7.85 \mathrm{~b}\end{array}$

3.2

8.97 a

4.8

$9.24 \mathrm{a}$

$\mathrm{LSD}_{0.05}$

0.529

Batör devri $\left(\mathrm{min}^{-1}\right)$

600

11.658 a

700

$9.245 \mathrm{~b}$

800

$7.994 \mathrm{c}$

900

$5.676 \mathrm{~d}$

$\mathrm{LSD}_{0.05}$

0.674

Aynı harfle gösterilen ortalamalar arasında $\mathrm{P}<0.05$ düzeyinde fark yoktur. Farklı harfle gösterilen ortalamalar arasında $\mathrm{P}<0.05$ düzeyinde fark vardır. 


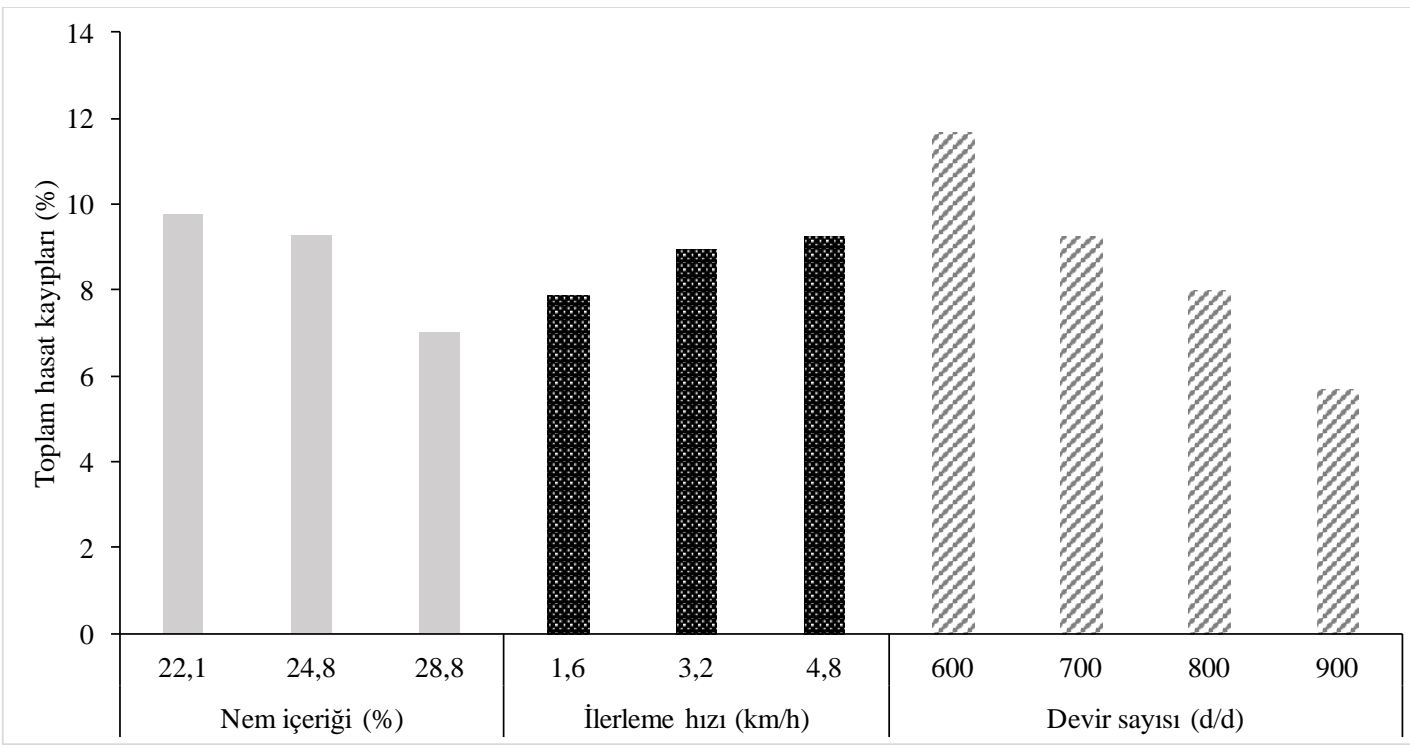

Şekil 5. Nem İçeriği, İlerleme Hızı Ve Batör Devir Sayısına Bağlı Olarak Toplam Hasat Kayıplarının Değişimi

Çizelge 3 ve Şekil 5 birlikte incelendiğinde ürün nem içeriği ve batör devir hızının artması toplam hasat kayıplarını azaltırken, biçerdöver ilerleme hızının artıșı hasat kayıplarını artırmıștır. \%24.81 ve \%22.10 ürün nem içeriklerinde elde edilen değerler arasında hem istatistiksel hem de rakamsal olarak önemli bir değişim olmamıştır. Yalnızca \% 28.85 ürün neminde elde edilen değer diğer nemlerden istatistiksel olarak farklı ve daha düşük bulunmuştur. Andrews ve ark. (1993) göre çeltik hasadı için en uygun hasat nemi \%19'dur. \%23 nemden sonra harmanlamanın kötüleştiğini bildirmiştir. Ancak, kayıpları azalmak için \%17-21 hasat neminin dikkate alınabilecek değerler olduğunu ifade etmişlerdir.

Buna karşın toplam hasat kayıpları üzerine biçerdöver ilerleme hızının etkisi ise artırıcı yönde olmuştur. İlerleme hızının $1.6 \mathrm{~km} \mathrm{~h}^{-1}$ den $3.2 \mathrm{~km} \mathrm{~h}^{-1}$ e yükseltilmesi durumunda istatistiksel olarak artış önemli bulunurken, $3.2 \mathrm{~km} \mathrm{~h}^{-1}$, den $4.8 \mathrm{~km} \mathrm{~h}^{-1}$,e yükseltilmesi durumunda ise rakamsal olarak artış olmasına rağmen, istatistiksel olarak bir fark oluşmamıştır (Çizelge 3). Sarkari (2010), ilerleme hızı ve besleme miktarının artışı dane kayıplarını artırmakta olduğunu bildirmiştir. Çalışmada elde edilen değerler ile Sarkari (2010), çeltikle farklı ilerleme hızı ve batör devir sayılarında yürütmüş olduğu çalışmasında elde ettikleri değerlerle oldukça benzerlikler göstermiştir.

Harmanlama işlemi dane kayıp ve kalitesi üzerine etkili önemli işlemlerden birisidir. Çeltik diğer taneli ürünlere göre salkımdan daha zor ayrılmaktadır. $\mathrm{Bu}$ nedenle yüksek bir çarpma etkisi gerekmektedir. Bunu sağlamak için parmaklı tip batör ve 700-1050 $\mathrm{min}^{-1}{ }^{1} \mathrm{l} \mathrm{k}$ batör devri önerilmektedir (Andrews ve ark., 1993; Behera ve ark., 1990; Roy ve ark., 2003). Şekil 5 ve
Çizelge 3 ' de görüldügü gibi hasat kayıpları batör devir sayısından önemli oranda etkilenmiştir. Devir sayısının artışına bağlı olarak toplam kayıplarda önemli oranda düșüs meydana gelmiștir. Bütün devirler arasındaki fark istatistiksel olarak önemli olmuştur. $600 \mathrm{~min}^{-1}$ da toplam hasat kayıpları \%11.67 iken, bu oran $900 \mathrm{~min}^{-1}$ a yaklaşık 2 kat azalarak \%5.67'ye düşmüştür. Benzer değerler Sarkari (2010), Behera ve ark. (1990) tarafından elde edilmiştir. Sarkari (2010), çeltik için en uygun batör devir sayınsın $850 \mathrm{~d} / \mathrm{d}$ olduğunu belirlemiştir. Bunun altındaki değerlerde dane kayıplarının arttığını ifade etmiştir. $\mathrm{Bu}$ değerler araştırmacının sonuçlarıyla uyumludur. Ayrıca, Anonymous (2008), çeltik hasadı için uygun çalışma neminin \% 17-21 arasında olması kırık dane kayıplarının azaltılması bakımından yararlı olabileceğini belirtmişlerdir.

Toplam makine kayıpları için tüm deneme kombinasyonları ayrı ayrı değerlendirildiğinde en düşük değerin \%28.85 nem, $4.8 \mathrm{~km} \mathrm{~h}^{-1}$ ilerleme hızında ve 900 $\min ^{-1}$ l lik batör devir hızında \% 3.41, en yüksek değer ise \%24.81 ürün nem içeriğinde $4.8 \mathrm{~km} \mathrm{~h}^{-1}$ biçerdöver ilerleme hızında ve $600 \mathrm{~min}^{-1}$ lık batör devrinde $\% 15.85$ olarak gerçekleşmiştir. Hasat öncesi kayıplarının ilave edilmesiyle oluşan toplam hasat kayıpları için tüm deneme kombinasyonlarının etkisi ayrı ayrı değerlendirildiğinde en düşük hasat kaybı değeri \% $28.85 \mathrm{nem}, 4.8 \mathrm{~km} \mathrm{~h}^{-1}$ ilerleme hizında ve $900 \mathrm{~min}^{-1}$ l $1 \mathrm{k}$ batör devir hızında \% 4.00 olarak, en yüksek değer ise $\% 24.81$ ürün nem içeriğinde $3.2 \mathrm{~km} \mathrm{~h}^{-1}$ biçerdöver ilerleme hızında ve $600 \mathrm{~min}^{-1}$ lık batör devrinde \%16.97 olarak gerçekleşmiştir. Buna karşın \%22.10 nem'de hemen hemen aynı değerler elde edilmiştir. 
Roy ve ark. (2003), Malezya'da doğrudan biçerdöverle yapmış olduğu çeltik hasadında toplam hasat kayıplarını \%5.6 olarak elde etmişlerdir. Benzer sonuçlar Hiregoudar ve ark. (2011) çeltik ile yürütmüş oldukları çalışmalarında makine ilerleme hızı ve devir sayısının artışına bağlı olarak biçme, harmanlama, ayırma ve temizleme kayıplarının arttığı, en yüksek kayıpların hasat ve harmanlama ünitesinde oluştuğunu bildirmişlerdir. Domeika ve ark. (2008), çalışmalarında kanola da hasat kayıları kesme, ayırma, temizleme ve harmanlama boyunca oluşan dane kaybı \%5-10'a ulaştığını; bu kayıpların \% 80-90'nının biçme ve ayırma düzeninde tekabül ettiğini belirlemişlerdir. Andrews ve ark. (1993) iki farklı çeltik çeşidi ve hasat döneminde aksiyal akışlı bir biçerdöverle yürütmüş oldukları çalışmada makina ilerleme hızının (besleme miktarı) ve rotor devir hızının hasat kayıpları üzerine önemli oranda etkili olduğunu ve bu etkinin çeşit ve zamana göre değiştiğini ifade etmişlerdir. Ancak, ilerleme hızının etkisi batör devir sayına göre daha fazla olduğunu, ayrıca, çeltik hasat kayıpları açısından için en uygun batör devir hızının $850 \mathrm{~d} / \mathrm{d}$ olduğu belirlemiş̧lerdir. Anonymous (2008), Arkansas çeltik üretim istasyonunda farklı çeşitle yürütmüş oldukları çalışmada çeltik için uygun batör devrinin $850-1000 \mathrm{~d} / \mathrm{d}$ arasında olduğunu bildirmişlerdir. $\mathrm{Bu}$ değer çalışmamızda seçtiğimiz $800-900 \mathrm{~min}^{-1}$ daki değerlerle oldukça benzerlikler göstermiştir. Yine, Arkansas çeltik üretim istasyonunda çeltikle yürütülen bir çalışmada biçerdöver ilerleme hızı arttıkça ürün hasat kaybının arttığını tespit etmişlerdir. Bu artışın, yüksek ilerleme hızdan dolayı besleme miktarının artışı ve dolayıyla sarsaklarda meydana gelen aşırı yüklenmeden dolayı oluşan harmanlama ve ayırma kayıplarının neden olduğu ürün kayıpları olduğunu bildirmiş̧lerdir.

\section{Sonuç ve Öneriler}

Ürün nem içeriğinin azalışı makine kayıplarını artırmıştır. $\mathrm{Bu}$ artış istatistiksel olarak \%28.85 nem içeriği ile diğer nemler arasında meydana gelmiştir. $\% 24.81$ ile \%22.10 nemler arasında herhangi bir fark oluşmamıştır. Buna karşın biçerdöver ilerleme hızının artışı makine kayıplarını artırmıştır. $1.6 \mathrm{~km} \mathrm{~h}^{-1}$ ilerleme hızında makine kayıpları \%6.74 iken bu değer $4.8 \mathrm{~km} \mathrm{~h}^{-}$

${ }^{1}$ ilerleme hızında \%7.86 olmuştur. Buna karşın, batör devir sayısının artışına bağlı olarak harmanlanmayan salkım şeklindeki dane miktarı azaldığından, makine kayıplarında da önemli oranda azalma meydana gelmiştir. Örneğin bu azalma $600 \mathrm{~min}^{-1}$ l $1 \mathrm{k}$ devirde makine kayıpları \%10.55 iken bu değer kademeli olarak azalmış ve $900 \mathrm{~min}^{-1}$ da bu değer 2.3 kat azalarak $\% 4.57$ 'e düşmüştür.

Ürün nem içeriği ve batör devir hızının artması toplam hasat kayıplarını azaltırken, ilerleme hızının artışı ise toplam hasat kayıplarını artırmışıtır. \%24.81 ve $\% 22.10$ ürün nem içeriklerinde elde edilen değerler arasında hem istatistiksel hem de rakamsal olarak pek bir değişim olmamıştır. Yalnız \%28.85 ürün neminde elde edilen değer diğer nemlerden istatistiksel olarak farklı ve daha düşük bulunmuştur. $\mathrm{Bu}$ durum biçerdöverle çeltik hasadı için uygun çalışma neminin $\%$ 22-24 arasında olması dane kayıplarının azaltılması bakımından yararlı olabileceği ifade edilebilir. Buna karşın toplam hasat kayıpları üzerine biçerdöver ilerleme hızının etkisi diğer bir deyişle besleme miktarının etkisi ise artırıcı yönde olmuştur. İlerleme hızının $1.6 \mathrm{~km} \mathrm{~h}^{-1}$ den $3.2 \mathrm{~km} \mathrm{~h}^{-1}$ e yükseltilmesi durumunda istatistiksel olarak artış önemli bulunurken, $3.2 \mathrm{~km} \mathrm{~h}^{-1}$ 'den $4.8 \mathrm{~km} \mathrm{~h}^{-1}$ e yükseltilmesi durumunda ise rakamsal olarak artış olmasına rağmen, istatistiksel olarak bir fark oluşmamışıır. Hasat kayıpları batör devir sayısından oldukça önemli oranda etkilenmiştir. Devir sayısının artışına bağlı olarak toplam hasat kayıplarında önemli oranda düşüş meydana gelmiştir. Bütün devirler arasındaki fark istatistiksel olarak önemli olmuştur. 600 $\min ^{-1}$ da toplam hasat kayipları \%11.67 iken bu oran $900 \mathrm{~min}^{-1}$ a yaklaşık 2 kat azalarak \%5.67'ye düşmüştür.

Makine ilerleme hızının etkisi artırıcı yönde olurken, batör devrinin etkisi azaltıcı yönde olmuştur. Makine ilerleme hızının artışı ayırma kayıplarını artıırken, batör devir sayınsın artışı ayırma kayıplarını azaltmıştır. $\mathrm{Bu}$ artış doğrusal olmuştur.

Ayırma kayıpları için tüm deneme kombinasyonları ayrı ayrı değerlendirildiğinde en düşük değer $\% 22.10$ nem, $3.2 \mathrm{~km} \mathrm{~h}^{-1}$ ilerleme hızında ve $900 \mathrm{~min}^{-1}$ l lk batör devir hızında \% 0.80 olarak, en yüksek değer ise $\% 24.81$ ürün nem içeriğinde $4.8 \mathrm{~km} \mathrm{~h}^{-1}$ biçerdöver ilerleme hızında ve $600 \mathrm{~min}^{-1}$ lık batör devrinde $\% 15.28$ olarak gerçekleşmiştir.

Toplam hasat kayıpları için tüm deneme kombinasyonları etkisi ayrı ayrı değerlendirildiğinde en düşük hasat kaybı değeri \% 28.85 nem, $4.8 \mathrm{~km} \mathrm{~h}^{-1}$ ilerleme hızında ve $900 \mathrm{~min}^{-1}$ l1k batör devir hızında \% 4.00 olarak, en yüksek değer ise \% 24.81 ürün nem içeriğinde $3.2 \mathrm{~km} \mathrm{~h}^{-1}$ biçerdöver ilerleme hızında ve 600 $\mathrm{min}^{-1} 1 \mathrm{lk}$ batör devrinde $\% 16.97$ olarak gerçekleşmiştir.

\section{Kaynaklar}

Andrews, S.B., Siebenmorgen, T.J., Vories, E.D., Loewer, D.H., Mauromoustakos, A., 1993. Effects of Combine Operating Parameters on Harvest Loss and Quality in Rice. ASAE. Vol.36(6):1599-1607.

Anonyoums, 2008. www.knowledgebank.irri.org

Anonyoums, 2011. TUİK, http://www.tuik.gov.tr

ASABE, 2008. ASAE Standart S352.2, Moisture Measurement- Forages. Agricultural Engineering Yearbook. American Society of Agricultural Engineers, St. Joseph. MI, 49085. P.471

Baran, M.F., 2010. Kanolanın Hasat Mekanizasyonu ve Hasat Kayıplarının Saptanması Üzerine Bir Araştırma. Namık Kemal Üniversitesi Fen Bilimleri Enstitüsü Tarım Makinaları Anabilim Dalı Doktora Tezi. Tekirdağ. 
Behera, B.K, Dash S.K., Das D.K., 1990. Development and Testing of a Power-Operated Wheat Thresher. Agricultural Mechanization in Asia, Africa And Latin America. 21(4):15-21.

Chinsuwan, W., Chuan-Udom, S., Udompetaikul, V., Phayom, W., Panya, N., 1999. A Study on Harvest Losses of Hommali Rice Due to Manual Harvesting System and The Use of Combine Harvester. KKU Research Journal. 4(2): 4-12. (In Thai)

Chinsuwan, W., Pongjan, N., Chuan-Udom, S., Payom, W., 2003. Effects of Feed Rate and Threshing Speed on Performance of Axial Flow Thresher. ASAE Journal. 10(1): 9-14.

Chuan-Udom, S., Chinsuwan, W., 2007. Operating Parameters Affecting Threshing System Losses of An Axial Flow Rice Combine Harvester. Kku Research Journal. 12(4): 442-450. (In Thai)

Domeika, R., Jasinskas, A., Steponacıcıus, D., Vaiciukevicus, E., Butkus, V., 2008. The Estimation Methods of Oilseed Rape Harvesting Losses, Agronomy Research 6 (Special Issue), 191-198, 2008

Dilmaç, M., 1982. Biçerdöverlerde Tane Kayıplarının Nedenleri Ve Önlenmesi, Hasat Öncesi Ve Hasat Sonrası Ürün Kayıpları Seminer Bildirileri 13-17 Aralık, Ankara.

Güzel, E., Bayhan, Y., Ülger, A.C., 1991. Çukurova Bölgesinde Çeltik Hasat Mekanizasyonu Üzerine Etkili Bazı Parametrelerin Belirlenmesi. Tarımsal Mekanizasyon 13. Ulusal Kongresi Bildiri Kitab1, S.365377. Konya

Güzel, E., Özcan, M.T., Uğurluay, S., İnce, A., Sessiz, A., Kayışoğlu, B., 2010. Hasat-Harman Makinaları Ve İlkeleri. Adana Nobel Kitapevi. Adana.

Hiregoudar, S., Udhaykumar, R., Ramappa, K.T., Shreshta, B., Meda, V., Anantachar, M., 2011. Artificial Neural Network for Assessment of Grain Losses for Paddy Combine Harvester a Novel Approach College of Agricultural Engineering, Uas, Raichur, Karnataka, India, CCIS 140, Pp. 221-231.

Hofman, V., Wiersma, J., Allrich, T., 1978. Grain Harvest Losses. University of Minnesota, North Dakota State. Available

at: http://www.smallgrains.org/techfile/sept78.htm. Accessed 8 August 2005.

Jung, R., 1981. Measuring Soybean Harvesting Losses. Factsheet. Ministry of Agriculture, Food and Rural Affairs

Junsiri, C., Chinsuwan, W., 2009. Operating Parameters Affecting Header Losses of Combine Harvesters for Chainat 1 Rice Variety. Kku Research Journal. 14(3): 314-321.

Lesoing, G., 2001. Reduce Grain Harvest Losses. University of Missouri. http://extension.missouri.edu
Philbrook, B.D., Oplinger, E.S., 1989. Soybean Field Losses as Influenced by Harvest Delays Reprinted from Agronomy Journal Vol. 81, No. 2

Quick, G.R., 1992. IRRI. Engineering Contributions to Rice Dependent Agriculture. Agriculture Engineering Conference 1990. Proceedings Of A Conference Held in Toowoomba, Australia, 11-14 November .

Roy, S.K., Jusoff, K., Ismail, W.I.W., Ahmad, D., 2003. Performance evaluation of a combine harvester in Malaysian paddy field. Agricultural Mechanization in Asia, Africa and Latin America. 34 (4): 38-44.

Sarkari Mostofi, M.R., 2010. Field Evaluation of Grain Loss Monitoring on Combine JD 955. Advances in Environmental Biology, 4(2): 162-167, ISSN: 1995-0756 (C) 2010, American-Eurasian Network for Scientific Information.

Sarwar, J.G., and Khan, A.U., 1987. Comparative of RaspBar and Wire- Loop Cylinders for Threshing Rice Crop. Agricultural Mechanization in Asia, Africa And Latin America. Vol. 18(2): 37-42.

Sessiz, A., Güzel, E., Pınar. Y., 1994. Çeltiğin Biçerdöverle Hasadına Yönelik Bazı Parametrelerin Belirlenmesi. Tarımsal Mekanizasyon 15. Ulusal Kongresi, Cilt I, Antalya.

Sessiz, A., Ülger, P., 1998. Parmaklı Tip Aksiyal Akışlı Bir Harmanlama Ünitesinin Tasarımı ve Uygun Prototipin Geliştirilmesi Üzerine Bir Araştırma. Tarımsal Mekanizasyon 18. Ulusal kongresi, 17-18 Eylül. Tekirdağ, 1998.

Sessiz, A., Pınar, Y., 1999. Karadeniz Bölgesinde Çeltik Hasadı ve Hasat Sonrası. Karadeniz Bölgesi 1. Tarım Sempozyumu". Cilt I, 4-5 Ocak, Samsun

Sessiz, A., Pekitkan, F.G., Turgut, M.M., 2006. Hasat Kayıları, Nedenleri, Ölçme Yöntemleri Ve Azaltma Yolları. Tarımsal Mekanizasyon 23. Ulusal Kongresi, Çanakkale.

Siebenmorgen, T.J., Andrews, S.B., Counce, P.A., 1994. Relationship of The Height Rice Cut to Harvesting Test Parameters. Transactions of the ASAE. 37(1): 67-69.

Staton, M., Harrigan, T., 2008. Reducing Soybean Harvest Losses Soybean Facts September 2008, Msu Extension Agricultural Educator and Soybean 2010 Coordinator Associate Professor, Msu Biosystems Agricultural Engineering Department.

Sumner, P.E., 2004. Measuring Soybean Harvesting Losses Cooperative Extension Service the University of Georgia College of Agricultural and Environmental Sciences

Ülger, P., 1982. Buğday Hasat Harmanında Uygulanan Değişik Mekanizasyon Sistemlerinin Tane Ürün Kayılarına Etkileri. Hasat Öncesi ve Hasat Sonrası Ürün Kayıları Seminer Bildirileri 13-17 Aralık S.195-243 Ankara. 